\title{
THE EXPATRIATE AND TRANSNATIONAL DISTANCE STUDENT PHENOMENON: A MULTICASE STUDY OF WESTERN DISTANCE STUDENTS IN THE REPUBLIC OF KOREA
}

\author{
William H. Stewart ${ }^{1}$ \\ Hankuk University of Foreign Studies, Republic of Korea
}

\begin{abstract}
A lack of differentiation among student conceptualizations and the use of homogenous labels has made descriptions of distance students in the literature difficult to parse. While students in an online class may share the same nationality or citizenship, they may not share the same nation of residence or status of sojourn. Similarly, "local" students in transnational programs may in fact not be locals, and there is no clear consensus on what differentiates transnational versus international distance students. Such discrepancies have gained burgeoning recognition in recent years, yet related research is limited. This multicase study ultimately investigated the experiences of Western expatriate and transnational distance students situated in various cities throughout the Republic of Korea, highlighting themes of convenience, benefits, home-country orientation, and perceptions of a non-local future in their distance programs. Implications for both home- and host-country universities are discussed.
\end{abstract}

Keywords: distance students, transnational education, expatriates, Korea, globalization

\section{Introduction}

Distance education has evolved from being merely an educational practice into a rich field of study (Harasim, 2000). The field has also gone from being locally, regionally, or nationally focused (e.g., Mantilla Galvez, 2018; Moiseeva, 2005; Saba, 2011) to one that is increasingly inclusive of international and/or transnational settings (e.g., Andrews \& Tynan, 2010; Gemmell \& Harrison, 2017; Gunawardena, 2014; Gunawardena \& LaPointe, 2008; Selwyn, 2011; Singh et al., 2012; Stewart, 2019; Wilkins, 2016). The global expansion of, and access to, distance education has introduced more complicated student scenarios that have been overlooked and consequently under researched, however (Andrews \& Tynan, 2010;

${ }^{1}$ Correspondence: 107 Imun-ro, Dongdaemun-gu, Seoul 02450, South Korea; Email: wstewart@hufs.ac.kr 
Gemmell \& Harrison, 2017; Harrison et al., 2018; Hoare, 2012, 2013; Madge et al., 2015; Parrish \& Linder-VanBerschot, 2010; Smith \& Ayers, 2006; Wilkins, 2016). Distance students can be situated in interstitial, transnational spaces that are not necessarily obvious (Jones, 2017). One example of this trend, which highlights the blurred lines between national origin, language, and geographic location, can be seen in Massively Open Online Courses (MOOCs).

Demographic trends tend to portray the typical MOOC participant as relatively young, western, English-speaking, and male as evidenced in data from high profile north American MOOC providers such as HarvardX, MITx, edX, and Coursera (Christensen et al., 2013; Glass et al., 2016; Jiang et al., 2016; Nesterko et al., 2013; Veletsianos \& Shepherdson, 2016). However, while some of these characteristics can be correlated with the respective geographic location (i.e., North America) and linguistic profile (i.e., English-speaking) of the MOOC providers themselves (Veletsianos \& Shepherdson, 2016), the geographic data from these studies presents a more complex portrait. Further, the data suggests that this relationship is not necessarily the case overall. In the data from edX, Coursera, and HarvardX, roughly two-thirds of total participants were located outside of the United States, with one-third in the European region, and the remaining third distributed around the world (Christensen et al., 2013; Glass et al., 2016). In short, most students in American MOOCs from these aforementioned studies were not American. The subtlety of the relationship that students have with educational providers and their own geographic locations is equally applicable when considering conventional face-to-face and distance education programs and courses (see Dobos, 2011; Gemmell \& Harrison, 2017; Harrison et al., 2018; Rensimer, 2016; Stewart, 2017, 2019; Wilkins, 2016).

\section{The Problem}

While there may not be drastically different characteristics between students in a national context versus students that are not, their perspectives and characteristics have otherwise not been included in the conversation as a whole (Andrews \& Tynan, 2010; Harrison et al., 2018). Although cases of expatriate distance students, and transnational/international distance students are comparatively small to their national counterparts (see Allen et al., 2016) at present, reporting statistics themselves are not necessarily so straightforward. Students may not report their actual current addresses for a variety of reasons such as home-country orientation, administrative ease, or general convenience (Stewart, 2017, 2019). Even the Online Learning Consortium has noted that although institutions "serve very few international distance education students, less than $2 \%$ in any sector" an additional $3 \%$ reside in a location that is unknown to the institution (Allen et al., 2016, p. 15). Additionally, cases of distance students who straddle more than one country, are likely to grow through the currents of globalization and widespread use of modern transportation and information and communications technology (ICT) (Pieterse, 2007; Gunawardena \& LaPointe, 2008). Although "international" students have been conventionally conceived of as a form of educational migrant (Cha \& Chang, 2009), the phenomenon of expatriate and transnational students has only emerged in varying degrees in recent literature (e.g., Andrews \& Tynan, 2010; Gemmell \& Harrison, 2017; Harrison et al., 2018; Hoare, 2012, 2013; Stewart, 2017; Wilkins, 2016; Ziguras, 2008). However, this recognition is still underdeveloped and complicated by a lack of consistent and/or clear terms and definitions. 


\section{A Multiplicity of Terms}

The distinction between international distance students and transnational ones is unclear in the literature (Kosmützky \& Putty, 2016) as both terms share the same key characteristic: a student being located in a country different from where the awarding institution is based. Rensimer (2016) poignantly critiqued that " $[\mathrm{t}]$ he overlapping language of all things international-international students and international institutions in (inter)national spaces - appears to have made the term all but redundant as a useful research analytic in a globalizing era" (p. 79). Furthermore, the geographic location of the student or university alone does not adequately capture a wider range of possible relationships (Gemmell \& Harrison, 2017; Stewart, 2017). For example, neither of these two terms explicitly accounts for the possibility of expatriates which fall between national and international categories. And even when transnational distance student perspectives have shared their experiences, the cases themselves are not necessarily uniform typologically (see Singh et al., 2012). Additionally, similar to the term international, transnational is not used uniformly and requires readers to explicitly determine what is meant in individual scholarship (Pieterse, 2007). To address this complication, both Gemmell and Harrison (2017) and Stewart (2017) have called for the inclusion of the geographic location of students, their nationalities, and an administrative classification to better delineate them. As a result of current practices and conceptualizations, universities may be unable to report accurate data, which affects subsequent policymaking and ultimately the visibility of such students. Thus, the difference in student type is not only a technical or terminological one, but contextual.

This researcher posits that the distinction matters in several ways. First, since distance education enables a student to be untethered from a physical campus, the inclusion of data representing cross-border mobility would complement current reporting statistics such as those presented by the Online Learning Consortium in their tracking of distance education trends in the United States (see Allen et al., 2016). Moreover, in the mid 1980 s Bean and Metzner (1985) recognized different attrition trends among college students that ultimately resulted in making distinctions between students: traditional and non-traditional. The differentiation mattered as it then allowed for a better understanding of non-traditional student characteristics (i.e., older, studying part time, living off campus) and how to better support students succeed. Some researchers (e.g., Gemmell \& Harrison, 2017; Harrison et al., 2018, Stewart, 2019), have posited that there are similar nuanced differences with distance students, and specifically so from an analogous typological perspective (Stewart, 2017, 2019). One of the common features of distance students in either an expatriate or transnational classification is that they live outside of their countries of citizenship. Rensimer (2016) noted how similar discrepancies among expatriate students in the United Arab Emirates (UAE) were similarly overlooked, highlighting a "call for nuanced approaches to research on expatriate and international students and recognition of their differing constraints, needs, resources, and aspirations" (Rensimer, 2016, p. 93). Moreover, using specific and consistent typological definitions would allow for comparison between student types as Gemmell and Harrison (2017) did with regards to help seeking behavior among non-EU distance students and their British counterparts since "international" is too diverse a category (Madge et al., 2015; Rensimer, 2016; Stewart, 2017, 2019). In this study, Korea was used as the research context as microcosm of demographic, technological, and globalization-related changes where there are different socio cultural orientations between students and the host country.

\section{Background}

The population in Korea is predominantly an urban one spread out across seven major 
cities, in addition the capital-metropolitan area which is home to roughly 25 million people, about half the national population (CIA, 2019). Although an ethnically homogenous nation, the foreign resident population has grown from approximately 30-40,000 to over 2.5 million in a period of only 35 years (A. Kim, 2014; MoJ, 2016; Shin \& Moon, 2019; Socinet, n.d.). This change in the national makeup is notably rapid given the peninsula's 5000 years of otherwise relative homogeneity (C. Kim, 2017). Moreover, the changing demographic trends have given rise to a foreign-resident population that includes more than just unskilled migrant labor from China and East Asia which has traditionally characterized the immigrant population (Shin \& Moon, 2019). Nevertheless, governmental policies have not recognized these growing changes (Shin \& Moon, 2019), and the educational needs/goals of certain immigrant groups are not necessarily being recognized or met (Shen, 2019). Even Korean returnees, third culture kids, or members of the Korean diaspora that immigrate to Korea can experience a lack of appropriate or viable secondary and tertiary education opportunities due to differences in educational systems, linguistic capabilities, and prior socio cultural knowledge (Greenholtz \& Kim 2009; S. Kim, 2018; Pollock \& Van Reken, 2009, Seol \& Skrentny, 2009). Shin and Moon (2019) have called for research that examines the "heterogeneity and multiplicity of migrants in Korea within the broader categories of migrant workers" (p. 603). This study's aims were twofold: contribute to calls by Shin and Moon (2019) by investigating a subset of the foreign population, and Rensimer (2016) by examining cases of long-term foreign residents who chose to study "abroad" online. Or more succinctly put, the phenomenon of expatriate and transnational distance students as manifest in Korea.

To date in Korea, the academic literature includes research on foreign residents in varying capacities (Shin \& Moon, 2019) who are academics (Froese, 2012), corporate workers (Jun \& Gentry, 2005), international students (Jon et al., 2014; Lee, 2011), marriage migrants (A. Kim, 2014), and ethnic returnees (Greenholtz \& Kim, 2009; S. Kim, 2018; Seol \& Skrentny, 2009). Missing from this literature base are studies on how adult foreign residents pursue education. Stewart (2017) preliminarily recognized a subset of foreign residents who chose to study online rather than enroll in local national or transnational programs, but the study was limited to exploring demographic and program characteristics. What these students' experiences were like, if/how they applied knowledge locally, or what their motivations for doing so, were unclear. Further, there were local opportunities available in the form of Korean and transnational programs in their chosen fields of study, taught in their desired language (English). Moreover, the experience of studying at a distance while situated in a culture distinctly different from one's own is under described in the literature (Harrison et al., 2018). Thus, the impetus for this multicase study was to build on top of Stewart's (2017) exploratory descriptive study, and calls from other researchers (e.g., Andrews \& Tynan, 2010; Harrison et al., 2018; Gemmell \& Harrison, 2017; Rensimer, 2016; Shin \& Moon, 2019) by investigating cases of distance students that may look similar to their national or "international" counterparts, yet are typologically different. Additionally, it would contribute to scholarship in the Korean context where a paucity of research exists on the growing foreign-born population (Shin \& Moon, 2019).

\section{Methodology}

As a qualitative approach and multicase study method, this researcher took the same philosophical view that Stake (2006) does where knowledge-building and meaning-making are viewed as interpretive and constructive acts, and where the researcher attempts to document these experiences in collaboration with the participants by interpreting them. Moreover, the target cases aligned appropriately with a multicase method as the particulars 
of the case could be investigated, and where the cases were bound to one another categorically (Stake, 2006) by three traits: national origin of student/university, sojourn status in the host country, and actual geographic location of student/university. And since variation along these dimensions was considered possible, a multiple case approach was an appropriate research design to capture potential variation (Yin, 2009).

\section{Definition of Terms}

Since the literature is inconsistent in both terminology and definitions (e.g., home student, domicile student, national student, expatriate, home student abroad, international student, transnational student) (see Madge et al., 2015; Kosmützky \& Putty, 2016; Rensimer, 2016; Stewart, 2017, 2019), Stewart's (2017) conceptual model was used to delineate and target expatriate and transnational cases only (see Figure 1). While the four cases identified in the model are indeed similar, the descriptive differences are ones of that have often been overlooked (Gemmell \& Harrison, 2017; Rensimer, 2016). For example, an expatriate would be classified as a regular student at a university in their home country despite the fact they are living elsewhere in the world. Moreover, that particular place may contextually differ in ways that affect their status as a student. For example, Western Anglophones living in another Anglophone country would have a shared language and some common cultural background, whereas in this study, participants were Anglophone Westerns living in an ethnically homogenous Asian country with no common language or shared socio cultural heritage.

\begin{tabular}{|l|l|}
\hline \multicolumn{1}{|c|}{ National } \\
$\begin{array}{l}\text { A national/citizen of country A, attending } \\
\text { university online in country } \mathbf{A} \text {, while living in } \\
\text { country A. Designated as a regular student by } \\
\text { the University. }\end{array}$ & $\begin{array}{l}\text { A national/citizen of country A, attending } \\
\text { university online in country } \mathbf{B} \text {, while living in } \\
\text { country A. Designated as an international } \\
\text { student by the University }\end{array}$ \\
\hline \multicolumn{1}{|c|}{ Transnational } \\
$\begin{array}{l}\text { A national/citizen of country } \mathbf{A} \text {, sojourning } \\
\text { via a non-tourist visa in country } \mathbf{B} \text {, attending } \\
\text { university online in country } \mathbf{C} \text {. Designated as } \\
\text { an international student by the University. }\end{array}$ & $\begin{array}{l}\text { A national/citizen of country A, sojourning via } \\
\text { a non-tourist visa in country } \mathbf{B} \text {, attending } \\
\text { regular student by the university. }\end{array}$ \\
\hline
\end{tabular}

Figure 1. Stewart's Model of Distance Students

\section{Research Questions}

The multicase study was guided by a relatively narrow scope of five research questions:

RQ1. What are the demographic and program characteristics of expatriate and transnational distance students in Korea? 
While characteristics of distance students, and particularly traditional vs. non-traditional students have been described in the literature (see Bean \& Metzner, 1985), the objective was to differentiate the characteristics by case as proposed in the conceptual model and see if there were any common or notable characteristics across cases.

RQ2. What is the experience like of studying 'abroad' while living in a foreign country and culture?

Similarly, since expatriates and transnational students ultimately share an immigrant status in their respective host countries, this researcher felt it important to investigate what the experience was like compared to distance students who are conventionally viewed (or possibly assumed) to be studying in the relative comfort of their home countries and societies.

RQ3. What are any notable experiences that expatriate and transnational distance students have in their programs/courses?

As an extension of the previous research question, the intent of this question was to investigate notable aspects of the experience of studying in a host-country as foreign labour, unlike short term residential education with international students.

RQ4. Do students perceive any benefits of their academic program in their hostcountry?

Since the educational providers of expatriate/transnational students are based outside of the host-country, this question would shed light on any benefits, perceived or tangible, that result from their programs locally such as whether or not earned credentials result in higher pay/promotion or opening up more advantageous work opportunities.

RQ5. Do students apply what they have learned in the host-country's society?

And lastly, while immigrant/transnational communities can be marginalized or privileged groups relative to one another (see Kim, 2018; Lan, 2011), this researcher sought to investigate whether the knowledge and skills gained from these education programs would ultimately be applied in the host society, in any capacity given differences in language, careers, social status, etc.

\section{Case Selection Criteria}

To be eligible for participation, individuals needed to be residing in Korea, and be taking or have completed a distance program based outside of Korea. Therefore, the intention was to recruit participants from:

- multiple national/regional backgrounds and genders;

- who were studying online at universities located in various nations/regions;

- at various levels of study and in different fields;

- and at various stages in their programs.

Theoretical variation was considered to be an emergent characteristic of the study; 
the effort was made to translate the recruitment flyer into 20 languages which corresponded with the largest groups of foreign nationals (in descending order) as reported by the MoJ. The study was advertised through the Seoul Global Center (see SGC, n.d.), various social media groups, and professional organizations (e.g., chambers of commerce, KOTESOL, KORCOS). Korean citizens who were dual-citizenship holders (a relatively uncommon and recent phenomenon) blur these boundary conditions, and in the event of such a situation, would have been excluded from participation. The resulting participants, however, were ultimately from western, English speaking countries.

\section{Data Collection}

For the purpose of this study, a "case" was defined as a single foreign-resident who was or had been studying "abroad" while living in Korea. Data was collected over a twomonth period, and ultimately from eight foreign-resident distance students. The researcher followed an interview protocol with 16 questions (and numerous sub questions) focusing on experiences with their classes, the perceived benefits and utility of their program's applicability in Korea, and any notable experiences they might have had. Iterative adjustments were made to sub questions where appropriate (i.e., distinctions/gpa, modules/semesters). Interviews were scheduled in advance of being conducted, and generally lasted from 30-40 minutes. The researcher met participants for 1:1 interviews at various locations (Gunpo, Incheon, Seoul) in the capital metropolitan area $(\mathrm{n}=5)$, while interviews for participants living in cities along the southern coast of Korea (Busan, Gwangju, and Jeju Island) were conducted by telephone $(n=3)$ as a matter of practicality. The location of cities/participants are presented in Figure 2. Interviews were recorded and processed in transcription software with manual editing for correction/accuracy, and subsequently imported and organized in NVivo for memoing and coding. Initial analysis helped consider and determine the question of data saturation. Although it can be difficult to predict when data saturation is reached (Crouch \& McKenzie, 2006), Fusch and Ness (2015) pragmatically suggested that if a qualitative study is being guided by theoretical sampling and data saturation as in this study, researchers simply need to be "explicit regarding how data saturation is reached" (p. 1413). To that end, purposefully sampled and homogenous groups may present relatively similar information and enable saturation more quickly (Guest et al., 2006). Due to the homogeneity of participants, after six cases, information was relatively uniform with only minor variations of codes produced in interview seven and data collection was discontinued after interview eight.

\section{Data Analysis}

After initial code generation, codes were more formally established, along with case descriptions, including a preliminary cross-case analysis that compared/contrasted the cases (Stake, 2006). Four prevalent themes emerged describing: 1) convenience; 2) a home-country orientation; 3) a non-local future; and 4) perceived benefits of their programs.

\section{Validation Strategies and Trustworthiness}

The researcher followed an interview protocol for uniformity and kept a log of activities to document the sequence of research events to enable an audit trail (Lincoln \& Guba, 1985). Tentative case descriptions were sent to participants as a means of member checking so that they could "judge the accuracy and credibility of the account" and make changes before they were finalized (Creswell, 2013, p. 252). All participants approved their case descriptions and made appropriate modifications and feedback where they felt necessary. 
An overview of participant demographics and program characteristics, organized by distance student type, are presented in Table 1. Notable to this researcher is greater age compared to Bean and Metzner's (1985) definition of nontraditional students, the level of study, and the addition of status as a first-generation, foreign-born immigrant.

\section{Case Analyses}

Table 1. Overview of Distance Student Cases

\begin{tabular}{|c|c|c|c|c|c|c|c|}
\hline Nat. & $\begin{array}{l}\text { Uni. } \\
\text { Location }\end{array}$ & Gen. & Age & $\begin{array}{l}\text { Program } \\
\text { Type }\end{array}$ & $\begin{array}{l}\text { Participant } \\
\text { Location }\end{array}$ & $\begin{array}{l}\text { Program } \\
\text { Cost } \\
\text { (USD) }\end{array}$ & Field of Study \\
\hline \multicolumn{8}{|c|}{ Expatriate Distance Students } \\
\hline USA & Idaho & M & 36 & $\mathrm{PhD}$ & Gunpo & 30,000 & Administration \\
\hline USA & Indiana & $\mathrm{F}$ & 40 & $\mathrm{EdD}$ & Gwangju & 30,000 & LCLE \\
\hline USA & California & M & 45 & MA & Seoul & 55,000 & TESOL \\
\hline UK & England & $\mathrm{F}$ & 35 & MA & Busan & 15,000 & TESOL \\
\hline UK & England & M & 33 & $\mathrm{EdD}$ & Gunpo & 30,000 & Ed. Leadership \\
\hline \multicolumn{8}{|c|}{ Transnational Distance Students } \\
\hline USA & Australia & M & 42 & MA & Incheon & 26,000 & App.Linguistics \\
\hline USA & England & M & 34 & MA & Jeju & 15,000 & TESOL \\
\hline $\mathrm{CAN}$ & Scotland & M & 56 & MA & Seongnam & 10,000 & TESOL \\
\hline
\end{tabular}

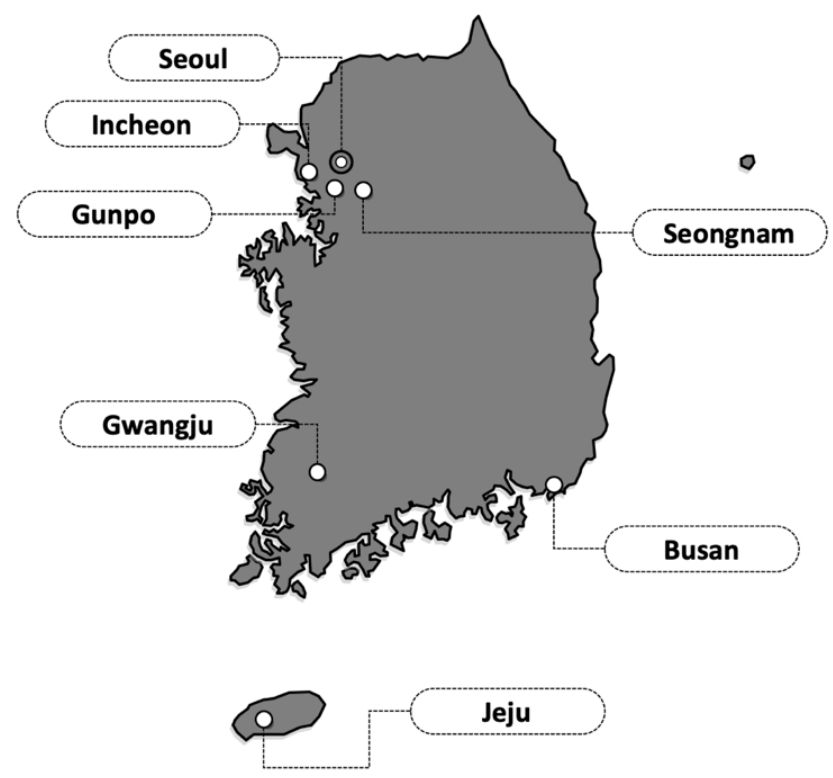

Figure 2. Map of South Korea and Participants' Locations 


\section{Expatriate Distance Students}

\section{Case 1 - Duncan, 33, English, 10-year sojourn, Ed.D. program}

Duncan (a pseudonym) had been struggling to find work in his early 20 s "because I'm inexperienced, too young, etc." and was "sick of getting knocked back from menial jobs in the UK, because they would constantly say, if you got a graduate school degree, you will leave at the very first opportunity, so we're not going to hire you". It had been suggested to him that in order to get international work experience relevant to NGO work, he might consider going abroad to teach English. Coupled with a passion for football, awareness of Korea from the 2002 World Cup, he came to Korea in 2008 to get experience in a career he had no prior interest in. At the time, he never would have imagined how much this suggestion would change his life as he would eventually get married, start a family, and settle down in Gunpo, a city just south of Seoul.

Although he arrived in Korea holding a graduate degree, Duncan would complete a second master's degree in education through a local face-to-face transnational degree program in order to better qualify as an educator. Moreover, it was a step and precursor towards pursuing a doctorate, eventually choosing an online EdD program at his alma mater in England. As a first-year doctoral student, he has been surprised by the overall positive experience, and the value it has added to his practices in the classroom. He expects to graduate around 2022.

\section{Case 2 - Corey, 36, American, 10-year sojourn, Ph.D. program}

In 2008, Corey (a pseudonym) was working at a bank in the United States in Washington State. He did not enjoy the work, and "I had a friend who was teaching English at a public school in Korea. And he said, my school is looking for a teacher to start next week. I know this sounds crazy, but you should come over here. Like it's the life you'll just totally love it. You'll never go back". He applied for the position and within a week, he had quit his job at the bank and was boarding a plane for Korea.

Three years into his sojourn, he got married, and five years in, he had his first of three children. It was at this time that Corey felt it would be a good decision to repatriate back to the United States with his wife and son, and rather strategically looked at industries where there was a need for qualified professionals, settling on higher education administration. Thus, if he earned a doctorate and state credentials prior to repatriating, he thought it would be easier to reintegrate into the workforce. While his experience in the program was overwhelmingly positive with an "unusually close cohort", his goal to repatriate to the U.S. ultimately changed as his "view on Korean education for young children has changed" and "I thought [Korea] is a place where I would prefer to raise my children. Near the end of my program, I soon, I started to see that the program equipped me with the tools to publish through my university and to engage and research in my, in my university, which is something that our department actively encourages". He graduated in April 2019 one week prior to participating in this interview.

\section{Case 3 - Trey, 35, English, 2-year sojourn, M.A. program}

Trey (a pseudonym) had always had an interest in Korea which was responsible for her travelling to the nation four times prior to moving to Busan for work. She had been curious about working in Korea, but she had no interest in teaching, and "didn't really want to be an English teacher" since she had had a career as a graphic designer. However, she did not enjoy living in London, and was unhappy with her job, and decided to use an English 
teaching position in Korea as a short term means of securing a work visa. Once in country, she would be able to more easily look for more appropriate or desirable work. Yet, "I actually realized how much I enjoyed teaching. So yeah, I, for the next, for the foreseeable future, that's [education] my career path". When asked about living in Korea and studying "abroad" online, she noted that she can easily seclude herself and focus on studying, and that the cost of living is much lower compared to London. She has also enjoyed the diversity of students in her program with peers from all over the world. However, she did not anticipate or realistically estimate how much work was actually involved in the program and often finds it exhausting. She expects to graduate in March 2020.

\section{Case 4-Selene, 40, American, 14-Sojourn, Ed.D. program}

Selene (a pseudonym) immigrated to Korea in 2005 because she was "crazy" about Asian cinema; upon her completion of a master's in cinema studies, she "had an idea that if I could go to Korea and study the language, master the culture, then I could go back, get a doctorate in film studies and become one of the foremost North American experts on Korean cinema because at that time, nobody was talking about Korean cinema, and I knew it was going to be huge". She looked into the Fulbright ETA program and thought "well, at least I'll be in Korea, I can take Korean language lessons and watch Korean movies while I'm there and learn about the culture. And, ugh, if I have to teach, I guess that's okay". Upon walking into her first classroom, however, she immediately fell in love with teaching, and her career goals completely shifted.

After three years of teaching, she pursued a CELTA, and four years after that she decided to pursue a second master's degree in Literature, Culture, and Language Education (LCLE). A couple of years after graduating, her LCLE program opened a distance EdD, and she jumped at the opportunity to enroll. Her experience thus far has been overwhelmingly positive: "My classmates are awesome. I love my cohort. They are the most supportive, generous group of people I've ever met. I absolutely love interacting with them online." They have even traveled to conferences and presented together. She currently has finished doctoral coursework and is preparing for comprehensive exams. She anticipates graduating in 2020.

\section{Case 5 - Toben, 45, American, 8-year sojourn, M.A. program}

Originally from southern California, Toben (a pseudonym) came to Korea to specifically to teach English. As a Korean-American, he was eligible for an ethnic heritage visa which allowed him to live and work freely unlike other visa types that are directly tied to an employer and/or particular industry. "After three and half years in Korea now that I'm looking back at my stuff from then, I felt that I'd reached a point that I needed more schooling to improve my teaching which is why I decided to do it at that time" and pursued a graduate degree in TESOL. He asked a number of professional acquaintances for advice and ended up choosing a program in his home-town area in the US that fulfilled a number of criteria: synchronous classes, classroom practicum, a US degree, and university ranking/reputation. Despite the time difference between Seoul and California, he would virtually attend classes several times per week at night around 10-11 pm. He also had the opportunity to do group work with other classmates who were similarly located on the peninsula. Upon graduating, he left Korea because "it was just time to try something, to, I just needed a break" and went on to pursue a second masters in the United Kingdom. 


\section{Transnational Distance Students}

\section{Case 6 -JT, 42, American, 15-year sojourn, M.A. in an Australian program}

In 2004, JT (a pseudonym) was living in Chicago and had become bored with life and disillusioned with work in a cubicle for an online university. While conducting job searches, he came across an advertisement for living and working abroad. He replied to the post, received a phone call 10 minutes later, and within two weeks had found a roommate to replace him in a sublet, his parents said they would take care of selling his car, and he boarded a plane to Korea. He would later get married in 2012 and had a daughter in 2013, but by the time she was two years old, he realized that his career in the nightlife and entertainment industry was not conducive or sustainable for raising a daughter since he would be away from home until five or six in the morning, four to five days a week.

A friend of his who worked at university said he could help get him a job teaching English there, but there was a condition attached; he had to enroll in a master's program immediately. He chose a program in Australia based on word of mouth and positive experiences from friends and coworkers who had taken the same program in years prior. He has found the program to be personally valuable since "it's giving me a very unique lens through which to view my life here as a [immigrant], my Korean is pretty good, but also, you know, living as a linguistic outsider. And just a more interesting awareness of those kinds of things". He anticipates graduating in 2020.

\section{Case 7 - Mike, 34, American, 8-year sojourn, M.A. in a UK (England) program}

Mike (a pseudonym) came to Korea in his mid-twenties for the purposes of teaching, the experience of living abroad, and the ability to travel. He ended up in Jeju Island, a province situated about $200 \mathrm{~km}$ south of the peninsular mainland. While starting work in Korea in the private academy system, he noted that "even before I came to Korea, I knew eventually I wanted to teach at the university level. And once I got some experience here, and I looked into the general requirements for teaching at universities in Korea, I thought that having a graduate degree would be very beneficial to me. So, I decided to pursue a master's program”. He enjoyed living in Jeju, developed a community of friends, and was not interested in relocating to attend classes (either domestically or abroad) and decided to enroll in a distance program located in the United Kingdom. He graduated in 2016.

\section{Case 8 - Rob, 56, Canadian, 20-year sojourn, M.A. in a UK (Scotland) program}

Rob (a pseudonym) came to Korea in the late 1990s for "work and adventure" and has been living and working in the capital-metropolitan area for 20 years. While the adventure part of his motivations has since subsided, he has continued to work in higher education. He had always planned on going to graduate school, but the programs available or accessible to him circa 2001 were very limited. He was planning on getting a master's degree in TESOL in order to repatriate to Canada. Ultimately, he looked to the British universities and chose to study at a program in Scotland since it was not only a renowned institution, but one he had an interest in due to his family's Scottish "heritage connection, however, tenuous it might be”. Rob, however, would not complete his program. For him:

It was not the easiest. The usual support systems that you would have in a, in a brick and mortar university simply weren't there. And even among our colleagues, there, there wasn't a lot of people you could turn to, if you, if you needed help, and like say, you know, face to face.

He also noted that an online course "plays to my very worst instincts of 
procrastination". Eventually he lost interest in the program and withdrew. In the end, "one of the exit points was a postgraduate certificate in education and that's what I got out of it... It wasn't it wasn't a complete flush". He would later complete an M.A. at face-to-face transnational program in 2016. He plans to return to Canada in 2019 or 2020.

\section{Cross-case Analysis}

\section{RQ1. What are the demographic and program characteristics of expatriate and transnational distance students in Korea?}

Aside from the common demographic characteristics of participants (western nationalities, English-speaking, mostly male) in this sample, most of the cases decided to pursue further education after a sojourn period of five to ten years (with Trey, Toben, and Rob being the exceptions at two to three and a half years). One common characteristic was their initial lack of credentials/qualifications in their professions. Though their reasons for immigration ranged from adventure, career change, and work, other reasons were more specific, such as becoming an expert in Korean cinema and getting international work experience for NGOs. Nevertheless, despite the variation in factors that led to immigration, participants found themselves funneled into the same niche industry due to limited employment options as non-Koreans and non-Korean speakers (Cooke \& Jiang, 2017), and as a function of national origin(s), native language, and prior college education (Collins, 2014).

These three qualifications easily enabled work visas in the EFL industry, regardless of their original intentions. Though working as English teachers was initially thought to be a temporary job for Stephen, Trey, and Selene, they were surprised at how much they enjoyed teaching and decided to make it a career. Similarly, Corey ended up enjoying education and dedicated himself to earning the related credentials, whereas for Mike and Rob, this had always been their goal. JT was working in the nightlife and entertainment industry but needed to change careers in order to better raise his young daughter. Thus, while they are all non-traditional students (see Bean \& Metzner, 1985), they possessed an additional layer of complexity as a result of their immigration status (i.e., visas and employment) and the nature of transnational education.

\section{RQ2. What is the experience like studying 'abroad' while living in a foreign country and culture?}

For the students (Stephen, Corey, Trey, Selene, Mike, and Rob) whose universities were located in significantly different time zones, they experienced only minor difficulties as a result; though the time difference between Korea and North America is coincidentally 1214 hours apart which inverts the mornings and evenings, supporting findings from prior research (see Ziguras, 2008). With the exception of Rob, all of the cases had overwhelmingly positive experience in their courses, especially the doctoral students (Corey, Selene). All programs were asynchronous with the exception of Toben who specifically wanted synchronous classes otherwise he would not have considered an online program. Selene noted that some parts of her M.A. in LCLE were too U.S. centric, but that her doctorate, by contrast, had been wonderfully personal and customized to her setting in Korea. Mike noted how his university in England was able to send him custom print materials from the library within a week, considering their support and services to be excellent. Their academic performance, whether characterized as a GPA (i.e., 3.5+) or a distinction (i.e., 60-70\%+), is 
very high and in line with prior research on graduate students in distance programs (see Colorado \& Eberle, 2010).

\section{RQ3. What are any notable experiences that expatriate and transnational distance students have in their programs/courses?}

Trey noted that the isolation and cheaper cost of living made it easier for her to work and study in Korea compared to London, though she noted how exhausting and overwhelming the coursework could be at times. Both Trey and Rob noted how the usual support structures (family, coworkers, and classmates) were not readily available or linguistically accessible, and as immigrants, could compound the difficulty of program work. Such constraints of expatriate students have often been an overlooked nuance (Rensimer, 2016). By contrast, Corey stated how incredibly important and valuable it was to have a wife and family that supported him throughout his $\mathrm{EdS}$ and $\mathrm{PhD}$ programs, and that "it's wonderful that technology has afforded the opportunities for people like me [immigrants/expatriates], who would not have previously been able to attain such a degree as either an MA an EdS or a PhD”. With a wife and three children, not working to attend school was not an option.

\section{RQ4. Do students perceive any benefit(s) from their academic program in their host country?}

While further education was not always necessary due to prior minimal qualifications, these cases all wanted to be eligible for better future employment opportunities both in Korea, in their home countries, and abroad. When compared other classes of immigrants (i.e., unskilled labor) (see Shin \& Moon, 2019), it is clear that these cases hold a fair degree of social privilege and human capital. However, their motivations for choosing to work abroad also reflect common economic drivers such as unemployment, underemployment (Duncan, Corey), and potentially debt in the case of many westerners from tertiary studies (Collins, 2014). Lan (2011) has speculated that the foreign English teaching industry (to a certain degree) is comprised of "economic migrants marginalized by a shrunken labour market in the West as a result of capital outflow and global outsourcing" (p. 1676). Nevertheless, the perceived benefits attached to "improved" employment opportunities are not necessarily so clear.

For example, Mike was able to meet his goal of employment at a local university, however the difference in pay or workload from his previous job in the public-school system was not significantly different. Duncan noted that when completing his EdD "I will earn an additional 100,000 won [90 USD] a month" and that the pay increase will take "another 4050 years to pay [the degree] off". He suspects that it will likely only help with job security versus actual career advancement; he works off yearly contracts like many non-permanent (i.e., contract based employment) employees in Korea, regardless of industry (Cooke \& Jiang, 2017). Despite these cases being highly credentialed (i.e., multiple bachelor's, master's, and terminal degrees, certificates, etc.), Duncan and Corey were very direct about the realities of a professional ceiling as foreigners.

Duncan stated that "the thing that potentially halts it [the doctorate] being useful is simply the ceiling of my own position as a foreigner" and that "I will not have the opportunity to enter those [higher] positions". As Cooke and Jiang (2017) have noted, "political and social attitudes towards immigrants, and the pecking order of the sending countries held (explicitly 
and implicitly) by the destination country's government and nationals" acts as a labor barrier (p. 55), and it affects certain groups more negatively/beneficially than others. These individuals fare better than their Central Asian or Southeast Asian counterparts. Nevertheless, all of the cases mentioned a possible benefit and value of the degrees for if-orwhen they return to their home countries, though paradoxically none of them had any definite plans to do so. Corey and Rob both had once decided to repatriate but those plans eventually changed. The current typical sojourn period of these cases is in excess of 10 years.

\section{RQ5. Do students apply what they have learned into the host country's society?}

As students, immigrants, and education workers, they do not necessarily intend to apply what they are learning from "abroad" in Korea. Their reasons for this vary, such as from being unsure of applicability for cultural reasons as Mike explained:

Some of the things I would like to do is, it's not as easy here in Korea, specifically, interacting with fellow students, I find that to be difficult sometimes to get certain students to want to speak with their fellow classmates, or do group activities or activities that involve moving around and interacting with other students, that can sometimes be difficult.

For Corey and Selene, applying knowledge and skills developed in their degree was not intended since Corey wanted to repatriate and specifically sought out American administrative credentials. Selene wanted intellectual challenge, but that did not preclude her from applying these skills to her classroom practices, noting that "I wasn't doing my best for my students, and I wanted them to have the absolute best possible experience". By contrast, Rob felt that the nature of his original master's program "they kind of sold it as being, you know, practical, but, but it wasn't, it was, you know, it was academic, it was theoretical" and he was left to figure out how to apply those concepts on his own.

\section{Discussion and Implications}

As this study explored two cases of distance students distinct from conventional national or international labels, it has highlighted the subtlety of certain differences among distance students at large that have been overlooked in prior scholarship, although the Western Anglophone characteristics across both cases does not differentiate expatriate/transnational categories much from one another. For example, participants were mostly living as unmarried skilled migrant laborers in Korea (see Shin \& Moon, 2019) and described lacking the usual support structures (i.e., family, friends, coworkers, immediate access to classmates) that their national (or international) counterparts would most likely have, often limited by language barriers. Moreover, their employment is precarious and of a lower tier since they typically only have non-permanent contractual positions available (Cooke \& Jiang, 2017) compared to their national counterparts.

While the conventional trends on migration to Korea do indeed reflect the foreign majority being unskilled laborers from China, this has started to change with immigrants, both skilled and unskilled, coming from other regions, as well as developed Western nations (Shin \& Moon, 2019). Traditional marriage migrant characteristics have also similarly started to change yet government policy has not recognized the changing demographics (Shin \& Moon, 2019). These shifts matter since the declining national birthrate in Korea is a significant issue (Anderson \& Kohler, 2013; Yoo \& Sobotka, 2009) and has resulted in not only a reliance on foreign labor, but enrollment shortfalls in education at all levels. While children or 1.5 generation immigrants can more easily integrate or assimilate into primary and elementary education creating a pathway to the tertiary level (Griffin et al., 2012), this is 
not necessarily the case for adults. Moreover, there are other subtle transnational motivations at play, notably the idea of repatriation whether realized or not.

\section{Understanding Transnational Motivations}

When situated across two countries, the concept of home, and which "home" is actually oriented to, is complex (Nowicka, 2007; Ralph \& Staeheli, 2011).These cases uniformly stated how much they appreciate and enjoy living and working in Korea and have made it home in numerous ways (marriage, property ownership, families, children, careers), yet education uniquely was sought out in the "other" home. On one hand, for universities outside of Korea, there is a niche student demographic that is not only willing, motivated, and capable of affording their programs, but one that also perceives their degree offerings as being convenient and beneficial, despite the geographic, time zone, and administrative burdens (i.e., degree apostilles, notarizations). Further, comparatively longer periods of sojourn (10-15 years) seem to have no effect on willingness to study online in their home countries, or other third-party countries in the case of transnational distance students. Notable as well is that the transnational distance students sought ought western Anglophone countries to pursue further studies which, in these cases, did not have much contextual difference with their expatriate counterparts.

\section{Local Financial and Human Capital Losses}

On the other hand, for universities within Korea these cases represent a loss to the local economy since the cost of these programs range from 10,000-55,000 USD. Capturing this segment of the population, even to a miniscule degree, would satisfy internationalization efforts by the Korean government, as well as help address declining enrollment from the nation's low birthrate. Moreover, the loss is not purely financial as students (particularly doctoral ones) are not necessarily networking or participating directly in the local academic community where they might collaborate on research and publish in conjunction with local scholars, and in association with local universities.

On a more practical level, since these students were also employed, and is important to recognize that in most cases, the visas are sponsored by their employers. Simply enrolling in school full time is not necessarily an option since student visas come with vastly more limited employment options. As such, local universities could benefit from offering English (as an international language) mediated programs online. At present, there seem to be few (if any) online options available despite the opposite being true for face-to-face programs at relatively large universities such as Seoul National University, Korea University, Yonsei University, or Hankuk University of Foreign Studies, which currently support thousands of foreign international students in English-mediated programs.

\section{Affordances and Privileges}

The participants in this study also represent a certain class of immigrant that has the ability to repatriate if so desired, unlike refugees or ethnic minorities facing various constraints that make returning to their place of origin impossible (Farrell et al., 2018). Real world socio economic and socio cultural differences ultimately make distance education a privileged choice or affordance in these cases, and they have certain advantages over other immigrant groups (Cooke \& Jiang, 2017). This characteristic can be seen in having employment that has allowed them to pursue education at a distance which others may be unable to even consider. The situations of other immigrants (e.g., Chinese, Uzbek, and Mongolian) and minority groups participating in distance education is worth pursuing in 
future research.

\section{Internationalization from Within}

Korean universities (and others in similar situations such as Japan) may not necessarily consider adult, nontraditional, foreign born, first generation immigrants as potential students and as a result, do not market to them or include them in higher education growth strategies. This habitus can result in a kind of information desert where potential students are simply unaware of options available to them, or even how to access information about educational opportunities (Iloh, 2018). This can be compounded by the inability to speak/read the local language. The vast majority of foreigners in Korea will be at the same linguistic disadvantage in this sense as Korean is not spoken outside of Korea (North Korea notwithstanding).

By contrast, there has been a considerable effort to recruit traditional "international" students from abroad and particularly from China (Choi et al., 2019; Jon et al., 2014), rather than looking within at a growing foreign born adult population, which is increasingly relied upon for labor (Cooke \& Jiang, 2017; Shin \& Moon, 2019). Education policy in Korea would benefit from adapting current policies and recruitment strategies in response to these demographic trends and the broader effects of globalization (Lee \& Rhee, 2019; Shin, 2012; Shin \& Moon, 2019). Local universities are missing numerous opportunities to internationalize from within, generate revenue, and to meet the needs of an increasingly diverse society (Cooke \& Jiang, 2017; Iloh, 2018; Shin \& Moon, 2019). The support infrastructure exists (to some degree) to provide counseling for adult immigrants wishing to enter the world of higher education in Korea by means of the Global Centers which exist solely to help foreign-residents integrate into Korean life and society, though they do not provide any kind of academic counseling at present (see SGC, n.d.).

\section{Adult Immigrant College Choice and Distance Education}

Though there was some variety in degree programs, many of these degrees are available in Korea, particularly those in, TESOL/EFL, or Applied Linguistics. Furthermore, such programs are offered at both well-known Korean universities (e.g., Sookmyung Women's University, Hankuk University of Foreign Studies, Seoul National University) and face-to-face transnational programs (e.g., Birmingham University, Framingham State University). Both local national and transnational programs are also comparatively less expensive due to government tuition subsidies, discounts, or scholarships for foreign nationals (Stewart, 2017). Thus, it is unclear how or why students are choosing their respective universities. While models of college choice do exist (e.g., Jackson Model, Chapman Model, Hanson and Litten Model), these describe the decision processes or phases that high school students and their families make towards high education (see Vrontis, et al., 2007). Related studies (e.g., Griffin et al., 2012; Nora, 2004) have looked at minority/immigrant high school students in the United States, however these perspectives, motivations, or conditions are not necessarily the same as adult immigrant graduate distance students, nor as those in the Korean context and is an open area of research.

\section{Conclusion}

This study makes a contribution to the academic literature by investigating distinct cases of distance students as called for in previous research (e.g., Kosmützky \& Putty, 2016; Rensimer, 2016; Gemmell \& Harrison, 2017; Harrison et al., 2018; Shin \& Moon, 2019; Stewart, 2017, 2019), and providing a glimpse into a subset of the foreign-resident 
population's experiences in Korea. The cases presented here illustrate general reasons for needing (lacking credentials, a condition of employment) or wanting (intellectual challenge, career change) further education. Further, the specific degree fields were contextually related to a lack of alternative career options as non-Korean speakers, or an easier path into one particular immigrant-centric industry in Korea by virtue of western origins (see Collins, 2014). The cases also present subtle constraints from being situated transnationally such as not having familial or institutional support structures due to living abroad that other types of distance students, as defined in this study (i.e., national, international), should generally have available. While this study may provide some insight, there are numerous avenues for further investigation, nor is it without limitations.

\section{Limitations}

Participants represented in this study were relatively homogenous, all coming from western English-speaking countries, working in the same field as function of their national origins and immigration purposes (education, TESOL), and studying similar topics (ECLE, TESOL, Applied Linguistics, Educational Leadership). Thus, when viewed in conjunction with the knowledge that the overwhelming majority of foreign residents in Korea are Chinese nationals or from the Asian region in general (see MoJ, 2016), there are clear boundaries with their experiences, and those of other foreign nationals. For example, there was a synergy between these students' work/careers in education and a need for higher qualifications, particularly in tertiary education that would not necessarily be the same for others.

Additionally, these cases were not compared against cases of foreign residents who immigrated to Korea for work but decided to enroll in Korean programs, or students who started programs (both distance and local) but withdrew (with the exception of Rob). Moreover, these students volunteered to participate (no compensation was offered) and represent both purposeful sampling and a self-selection bias which can disproportionately represent their views (Heckman, 1979). However, as a qualitative research approach, the findings are not meant to be generalizable, nor are they intended to be representative of all potential cases of expatriate or transnational distance students in Korea, the region, or elsewhere in the world.

\section{Future Research}

First, there is ample opportunity to explore the distance student experience of other foreign nationals (particularly Chinese as the largest immigrant group) in Korea Moreover, similar studies can be conducted elsewhere in the world to explore different contextual dynamics (e.g., Korean immigrants in Mexico) that have a greater degree of variation. This might be more easily achieved through a top-down approach where participants are identified and recruited through university databases versus locally. This should yield a greater potential variety of nationalities, genders, degree programs, and unique contextual locations. Since current college choice models are youth- and traditional student-centric (Iloh, 2018), a grounded theory study, for example, could suggest or approximate an explanation or "generate or discover a theory or abstract analytical schema of a phenomenon" that is "grounded in the experience and perceptions of the participants" (Creswell, 2015, p. 451). This approach could shed light on the motivations and decision-making process of expatriate and transnational distance students as manifest in Korea, and elsewhere in the world. 


\section{References}

Allen, I. E., Seaman, J., Poulin, R., \& Straut, T. T. (2016). Online report card: Tracking online education in the United States. Retrieved from http://onlinelearningsurvey.com/reports/onlinereportcard.pdf

Anderson, T., \& Kohler, H. P. (2013). Education fever and the East Asian fertility puzzle: A case study of low fertility in South Korea. Asian Population Studies, 9, 196-215.

Andrews, T., \& Tynan, B. (2010). Why the student voice? The case for investigating the distance learners' experience of ICT in distance education. In Proceedings ASCILITE 201 0: 27th Annual Conference of the Australasian Society for Computers in Learning in Tertiary Education: Curriculum, Technology and Transformation for an Unknown Future (pp. 60-64). University of Queensland.

Bean, J. P., \& Metzner, B. S. (1985). A conceptual model of nontraditional undergraduate student attrition. Review of Educational Research, 55, 485-540

Central Intelligence Agency [CIA]. (2019). Korea, South. In The world factbook. Retrieved from https://www.cia.gov/library/publications/the-world-factbook/geos/ks.html

Cha, M., \& Chang, W. (2009) Learning through working: A case study of Chinese college students in South Korea. Asia Pacific Journal of Education, 29, 31 1320. https://doi.org/10.1080/02188790903092803

Choi, J., Tatar, B., \& Kim, J. (2019). Bilingual signs at an 'English only' Korean university: Place-making and 'global' space in higher education. International Journal of Bilingual Education and Bilingualism, 1-14. https://doi.org/10.1080/13670050.2019.1610353

Christensen, G., Steinmetz, A., Alcorn, B., Bennett, A., Woods, D., \& Emanuel, E. J. (2013). The MOOC phenomenon: Who takes massive open online courses and why? HarvardX and MITx Working Paper No. 1. http://doi.org/10.2139/ssrn.2350964

Collins, F. L. (2014). Teaching English in South Korea: Mobility norms and higher education outcomes in youth migration. Children's Geographies, 12, 40-55.

Colorado, J. T., \& Eberle, J. (2010). Student demographics and success in online learning environments. Emporia State Research Studies, 46, 4-10.

Cooke, F. L., \& Jiang, Y. (2017). The growth of non-standard employment in Japan and South Korea: The role of institutional actors and impact on workers and the labour market. Asia Pacific Journal of Human Resources, 55, 155-176.

Creswell, J. W. (2013). Qualitative inquiry \& research design: Choosing among five approaches. Los Angeles, CA: Sage.

Creswell, J. W. (2015). Educational research: Planning, conducting, and evaluating quantitative and qualitative research. Upper Saddle River, NJ: Pearson/Merrill Prentice Hall.

Crouch, M., \& McKenzie, H. (2006). The logic of small samples in interview-based qualitative research. Social Science Information, 45, 483-499.

Dobos, K. (2011). 'Serving two masters'-Academics' perspectives on working at an offshore campus in Malaysia. Educational Review, 63, 19-35

Farrell, O., Brown, M., Brunton, J., Costello, E., Delaney, L., \& Foley, C. (2018). Can you give me sanctuary? Exploring the transition experiences of refugees and asylum seekers to online distance education learning. Proceedings of the 10th European Distance and E-Learning Network Research Workshop (pp. 24-26), Barcelona.

Froese, F. J. (2012). Motivation and adjustment of self-initiated expatriates: The case of expatriate academics in South Korea. The International Journal of Human Resource Management, 23, 1095-1112.

https://doi.org/10.1080/09585192.2011.561220

Fusch, P. I., \& Ness, L. R. (2015). Are we there yet? Data saturation in qualitative 
research. The Qualitative Report, 20, 1408-1416. Retrieved from http://www.nova.edu/ssss/QR/QR20/9/fusch1.pdf

Gemmell, I., \& Harrison, R. (2017). A comparison between national and transnational students' access of online learning support materials and experience of technical difficulties on a fully online distance learning master of public health programme. Open Learning, 32, 66-80. https://doi.org/10.1080/02680513.2016.1253463

Glass, C. R., Shiokawa-Baklan, M. S., \& Saltarelli, A. J. (2016). Who takes MOOCs?. New Directions for Institutional Research, 2015, 41-55.

Greenholtz, J., \& Kim, J. (2009). The cultural hybridity of Lena: A multi-method case study of a third culture kid. International Journal of Intercultural Relations, 33, 391398. http://doi.org/10.1016/j.ijintrel.2009.05.004

Griffin, K., Del Pilar, W., McIntosh, K., \& Griffin, A. (2012). “Oh, of course I'm going to go to college": Understanding how habitus shapes the college choice process of Black immigrant students. Journal of Diversity in Higher Education, 5, 96-111.

Guest, G., Bunce, A., \& Johnson, L. (2006). How many interviews are enough? An experiment with data saturation and variability. Field Methods, 18, 59-82.

Gunawardena, C. N. (2014). Globalization, culture, and online distance learning. In O. Zawacki-Richter \& T. Anderson (Eds.), Online distance education - Towards a research agenda. (pp. 75-107). Canada: Athabasca University Press

Gunawardena, C. N., \& LaPointe, D. (2008). Social and cultural diversity in distance education. In T. Evans, M. Haughey, \& D. Murphy (Eds.), International handbook of distance education (pp. 51-70). United Kingdom: Emerald.

Harasim, L. (2000). Shift happens: Online education as a new paradigm in learning. The Internet and Higher Education, 3, 41-61.

Harrison, R. A., Harrison, A., Robinson, C., \& Rawlings, B. (2018). The experience of international postgraduate students on a distance-learning programme. Distance Education, 39, 480-494.

Heckman, J. J. (1979). Sample selection bias as a specification error. Econometrica: Journal of the Econometric Society, 47, 153-161.

Hoare, L. (2012). Transnational student voices. Journal of Studies in International Education, 16, 271-286. http://doi.org/10.1177/1028315311398045

Hoare, L. (2013). Swimming in the deep end: Transnational teaching as culture learning? Higher Education Research \& Development, 32, 561-574. https://doi.org/10.1080/07294360.2012.700918

Iloh, C. (2018). Toward a new model of college "choice" for a twenty-first-century context. Harvard Educational Review, 88, 227-244.

Immigration and Social Integration Network [Socinet] (n.d.). Sahoi tonghap jeongbomang [Social integration program information]. Retrieved from http:// socinet.go.kr/

Jiang, S., Schenke, K., Eccles, J. S., Di Xu, \& Warschauer, M. (2016). Females' enrollment and completion in science, technology, engineering, and mathematics massive open online courses. CoRR, 1608, arXiv: 1608.05131

Jon, J. E., Lee, J. J., \& Byun, K. (2014). The emergence of a regional hub: Comparing international student choices and experiences in South Korea. Higher Education, 67, 691-710.

Jones, E. (2017). Problematising and reimagining the notion of 'international student experience'. Studies in Higher Education, 42, 933-943.

Jun, S., \& Gentry, J. W. (2005). An exploratory investigation of the relative importance 
of cultural similarity and personal fit in the selection and performance of expatriates. Journal of World Business, 40, 1-8.

https://doi.org/10.1016/j.jwb.2004.10.001

Kim, A. E. (2014). Global migration and South Korea: Foreign workers, foreign brides and the making of a multicultural society. Ethnic and Racial Studies, 32, 70-92.

Kim, C. (2017). The history of Korea. Westport, CN: Greenwood Press.

Kim, S. K. (2018). Illegitimate elites and the politics of belonging at a Korean university. Journal of Korean Studies, 23, 175-202. http://doi.org/10.1215/21581665-4339107

Kosmützky, A., \& Putty, R. (2016). Transcending borders and traversing boundaries. Journal of Studies in International Education, 20, 833. https://doi.org/10.1177\%2F 1028315315604719

Lan, P. C. (2011). White privilege, language capital and cultural ghettoisation: Western high-skilled migrants in Taiwan. Journal of Ethnic and Migration Studies, 3, 16691693.

Lee, D. Y. (2011). Korean and foreign students' perceptions of the teacher's role in a multicultural online learning environment in Korea. Educational Technology Research and Development, 59, 913-935. https://doi.org/10.1007/s 1 1423-011-9219-0

Lee, H. K., \& Rhee, B. S. (2019). Hybrid Internationalization in Korea: A Promising Development? International Higher Education, (96), 13-15.

Lincoln, Y. S., \& Guba, E. G. (1985). Naturalistic inquiry. Newbury Park, CA: Sage Publications.

Madge, C., Raghuram, P., \& Noxolo, P. (2015). Conceptualizing international education: From international student to international study. Progress in Human Geography, 39, 681-701.

Mantilla Gálvez, D. K. (2018). El impacto de la educación telesecundaria en México y su relación con la educación intercultural: El caso de la telesecundaria Tetsijtsilin en la Sierra Norte de Puebla [Tele-secondary education in Mexico and its relationship with intercultural education: The case of Tetsijtsilin Telesecundaria in the Northern Sierra of Puebla]. Tla-melaua, 12, 164-180.

Ministry of Justice [MoJ]. (2016). Korean Immigration Service statistics. 1-1055.

Retrieved from

http://www.immigration.go.kr/HP/COM/bbs_003/BoardList.do?strNbodCd=noti 0096\&strOrgGbnCd=104000\&strFilePath=imm/\&strRtnURL=IMM_6050\&strNb odCdGbn=\&strType $=\&$ strAllOrgYn $=\mathrm{N}$

Moiseeva, M. (2005). Distance education in Russia. The Quarterly Review of Distance Education, 6, 217-225.

Nesterko, S. O., Dotsenko, S., Han, Q., Seaton, D., Reich, J., Chuang, I., \& Ho, A. D. (2013). Evaluating the geographic data in MOOCs. In Proceedings of the 2013 NIPS DataDriven Education Workshop.

Nora, A. (2004). The role of habitus and cultural capital in choosing a college, transitioning from high school to higher education, and persisting in college among minority and nonminority students. Journal of Hispanic Higher Education, 3, 180-208.

Nowicka, M. (2007). Mobile locations: Construction of home in a group of mobile transnational professionals. Global Networks, 7, 69-86.

Parrish, P., \& Linder-VanBerschot, J. (2010). Cultural dimensions of learning: Addressing the challenges of multicultural instruction. The International Review of Research in Open and Distributed Learning, 11, 1-19. https://doi.org/10.19173/irrodl.v 1 1i2.809 
Pieterse, J. N. Â (2007). Global multiculture, flexible acculturation. Globalizations, 4, 65-79.

Pollock, D. C., \& Van Reken., R. (2009). Third culture kids: Growing up among worlds. Boston, MA: Nicholas Brealey Publishing.

Ralph, D., \& Staeheli, L. A. (2011). Home and migration: Mobilities, belongings and identities. Geography Compass, 5, 517-530.

Rensimer, L. (2016). International higher education for whom? Expatriate students, choicemaking and international (im) mobility in the Northern United Arab Emirates. Forum for International Research in Education, 3, 79-96.

Saba, F. (2011). Distance education in the United States: Past, present, future. Educational Technology, 51, 11-18.

Selwyn, N. (2011). "Finding an appropriate fit for me": Examining the (in)flexibilities of international distance learning. International Journal of Lifelong Education, 30, 367383. http://doi.org/10.1080/02601370.2011.570873

Seol, D.-H., \& Skrentny, J. D. (2009). Ethnic return migration and hierarchical nationhood. Ethnicities, 9, 147-174. http://doi.org/10.1177/1468796808099901

Seoul Global Center [SGC]. (n.d.). Seoul Global Center. Retrieved from http://global.seoul.go.kr/

Shen, S. (2019). Teaching 'multiculturally': Geography as a basis for multicultural education in Korea. Multicultural Education Review, 11, 37-58.

Shin, J. C. (2012). Higher education development in Korea: Western university ideas, Confucian tradition, and economic development. Higher Education, 64, 59-72.

Shin, G. W., \& Moon, R. J. (2019). Korea’s migrants: From homogeneity to diversity: An Asian survey special section. Asian Survey, 59, 595-606.

Singh, A., Cochrane, G., Uyar, Z., More, C., Scarcella, J., Yoshida, K., \& Mohammed, J. (2012). Transnational Distance Learning: A Student Perspective. In R. Hogan (Ed.) Transnational distance learning and building new markets for universities (pp. 6885). IGI Global.

Smith, D. R., \& Ayers, D. F. (2006). Culturally responsive pedagogy and online learning: Implications for the globalized community college. Community College Journal of Research and Practice, 30, 401-415. https://doi.org/10.1080/10668920500442125

Stake, R. E. (2006). Multiple case study analysis. New York, NY: Guilford Press.

Stewart, W. H. (2017). Recognizing the expatriate and transnational distance student: A preliminary demographic exploration in the Republic of Korea. Open Praxis, 9, 463481.

Stewart, W. H. (2019). The complexity of transnational distance students: A review of the literature. Open Praxis, 11, 23-29.

Veletsianos, G., \& Shepherdson, P. (2016). A systematic analysis and synthesis of the empirical MOOC literature published in 2013-2015. The International Review of Research in Open and Distributed Learning, 17, 198-221.

Vrontis, D., Thrassou, A., \& Melanthiou, Y. (2007). A contemporary higher education student-choice model for developed countries. Journal of Business Research, 60, 979-989.

Wilkins, S. (2016). Transnational higher education in the 21 st century. Journal of Studies in International Education [Editorial], 20, 3-7. https://doi.org/10.1177/1028315315625148

Yin, R. K. (2009). Case study research design and methods. Thousand Oaks, CA: Sage.

Yoo, S. H., \& Sobotka, T. (2018). Ultra-low fertility in South Korea: The role of the 
tempo effect. Demographic Research, 38, 549-576.

Ziguras, C. (2008). Cultural and contextual issues in the evaluation of transnational distance education. In T. Evans, M. Haughey, \& D. Murphy (Eds.), International handbook of distance education (pp. 639-653). United Kingdom: Emerald.

\begin{abstract}
About the Author
William H. Stewart, EdD, is currently an Inbound Exchange Student program manager at Hankuk University of Foreign Studies in Seoul, Korea. He completed a doctorate in Educational Technology (with a focus on distance education) from Boise State University. He has worked primarily in international and transnational education in both K-12 and higher education. His research interests are how distance education and transnational communities intersect, as well as student mobility and emerging trends in international education.
\end{abstract}

